The Janus Head Article - How Much Terminology

Theory Can Practical Terminology Management Use?

- BY: PETRA DREWER \& SYBILLE HOREND

Posted by Michael Lambarena on February 262009 12:06:35

\title{
The Janus Head Article - How Much Terminology Theory Can Practical Terminology Management Use?
}

The god Janus in Greek mythology was a two-faced god; each face had its own view of the world. Our idea behind the Janus Head article is to give you two different and maybe even contradicting views on a certain topic. This issue's Janus Head Article, however, features not two but three different views on terminology work, as researchers, professionals and students (the professionals of tomorrow) discuss "How Much Terminology Theory Can Practical Terminology Management Use?" at DaimlerChrysler AG.

\section{Overview}

Recent years have seen the rising importance of terminology work[1] within business enterprises, a trend that has been particularly fuelled by increasing globalization. A few decades ago, only trained terminologists and translators concerned themselves with the problems involved in developing unambiguous terminology. Today, however, many companies have realized that professional terminology management can decisively boost their competitiveness. This is particularly important in the public image areas of Customer Communication and Corporate Language.

The result of these developments can be seen through the gradual implementation of what has already been learned from terminology theory and research, and the increasing relevance of terminology studies at colleges and universities.

In a cooperative project between DaimlerChrysler AG (DC) and the Karlsruhe University of Applied Sciences, we allowed theory and practice to clash and examined the particular day-to-day 
terminological challenges faced by the "Language Technology Processes and Methods" team at DaimlerChrysler.

Does everything taught by terminology theory prove true in the real terminology-management world? Of course not. But precisely where do theory and practice contradict one another? And what are the reasons for such deviation?

\section{The Semiotic Triangle}

The foundation of terminology theory can be summarized by the semiotic triangle, which was introduced to linguistics by Ogden and Richards in the 1920s. The primary propositions illustrated here are also reflected in the relevant standards for the field of terminology, such as ISO 704 and ISO 860.1

\section{THOUGHT OR REFERENCE}

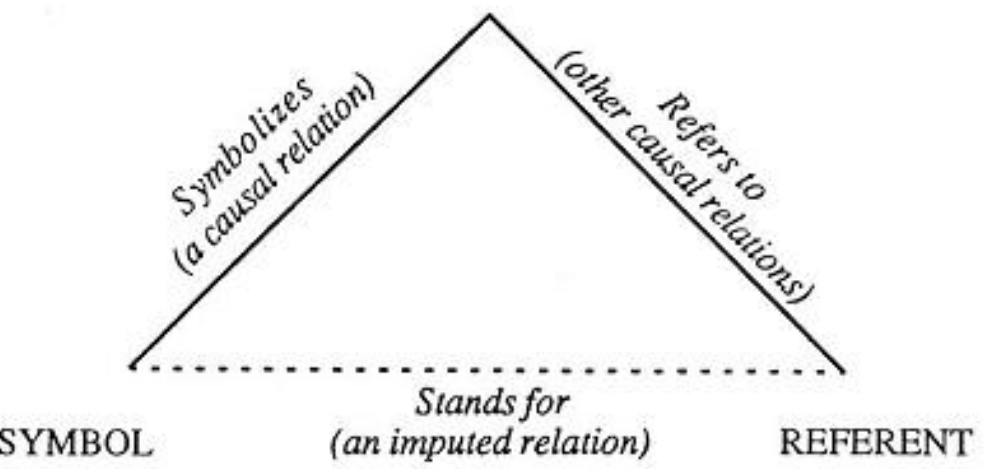

Fig. 1: Semiotictriangle by C.K. Ogden and I.A. Richards

Not every individual object in the world is differentiated and named. Instead, through a process of abstraction called conceptualization, objects are categorized into mental constructs or units-of-thought called concepts. These concepts are named.

Therefore, a language symbol (a word, a designation) is not directly connected with its referent in the world (the object). This connection is indirect (imputed), through a mental representation (the concept) of the element of the world.

${ }^{1}$ In these standards, the following terminology is used: symbol = designation, referent = object, thought/reference $=$ $\infty$ ncept.

\section{Requirements for Professional Terminology Management}

According to ISO $704 / 2000: v i$, the main activities in terminology management include:

- Identifying concepts and concept relations;

- Analysing and modelling concept systems on the basis of identified concepts and concept relations;

- Establishing representations of concept systems through concept diagrams;

- Defining concepts;

- Attributing designations (predominantly terms) to each concept in 
one or more languages;

- Recording and presenting terminological data, principally in print and electronic media (terminography)."

Terminology work is thus done on both the concept and designation levels. As terminological consistency is a high priority within businesses, the 5th item above involves a step toward standardization following the prescriptive phase. Where competing synonyms are found, one preferred term is selected in each language. This preferred term from that point on is the only admitted term. All other designations for the same concept are recorded in the terminology management system, but are marked as "invalid" or "deprecated".[2]

It is important that this data be managed in a concept-oriented manner, so that technical writers and translators can use terminological data effectively. In other words, each data record should contain one and only one concept, or at least one precise definition, and all designations that may potentially name this concept. A status is assigned to each designation (e.g. deprecated term, preferred term, etc.). This basic structure may be appended by the following items to improve the quality of the entry: illustrations, grammatical information, contextual information, status of entire entry, remarks, part numbers, subject field information, validities, etc.

\section{Positive Effects of Professional Terminology Management}

A company employing professional terminology management is rewarded with a well-organized collection of in-house nomenclature and of special-purpose terminology related to the company's field of operation. This terminology is standardized as much as possible to minimize the number of homonyms, polysemes and synonyms.

The consistent implementation of this systematic terminology can first of all improve the quality of texts (both source and target texts) with regard to the following aspects:

- Unambiguity

- Consistency

- Readability

By contrast, uncontrolled terminology can result in problems such as misplaced orders, misunderstandings and communication problems between buyers and suppliers or between employees in different departments, all because each group is using its own terminology.

Another primary reward of high terminological consistency lies in 
the improved translatability of texts. First of all, this makes the texts more understandable for the human translator eliminating the need for time-consuming and unnecessary research. In addition, the use of a centrally managed terminology system serves to reduce the workload of all translators (both in-house and external). The versatility and accuracy of translation memory systems also increase, since consistent terminology means a higher number of matches (translation memory systems cannot identify synonyms, since they can only compare formal and not semantic characteristics). Terminology mismatches between text modules in content management systems can likewise be avoided, and consistent terminology can even serve to improve a business's legal security.

\section{Terminology Management at DaimlerChrysler AG}

In order to give terminology work the priority it deserves, the Aftersales Division at DaimlerChrysler (DC) has set up a team known as "Language Technology Processes and Methods", to deal with the preparation and processing of terminology. A number of external service providers give DC's internal staff support on a variety of major issues.

Terminology preparation involves more than just researching and validating the correct designations for particular concepts and placing this information into a specially designed database. The staff responsible must also ensure that this terminology is disseminated in a methodical manner. In order to do so, the various CMS systems employ a controlled language checker (CLAT - Controlled Language Authoring Technology), which is also managed by the Language Technology Team.

Since August 2006, this team has been assigned to the Basic Documentation/Operating Instructions Department within the Technical Information/Workshop Equipment Section of DC's Global Service and Parts unit. With explicit management support, the Language Technology Team serves the entire section and thus has an influence that goes well beyond the limits of its own department, which is responsible for establishing other basic documentation guidelines and materials and for the production of operating instructions.

In order to ensure a smooth workflow and to meet the internal quality requirements of DC, the team developed its own terminology database, which allowed for the storage of special attributes (beyond definitions and synonyms) and for links to other basic documentation applications relevant to the section's work. A 
hierarchical system for breaking a vehicle down into its component parts was developed, so that texts dealing with specific parts of a vehicle (such as repair instructions) could be systematically assigned to the relevant section of the vehicle. The purpose here was to facilitate document searches. Terminological concepts are also linked to this breakdown. In other words, each concept is assigned to one or more vehicle elements.

Currently, many departments within DC maintain their own terminology collections in many different forms. The Language Technology Team has set itself the task of systematically integrating these terminological "finds". The objective of this work is to help make workshop documentation (including diagnostic texts, repair instructions and wiring diagrams) and customer information (such as operating manuals in both print and electronic form, as well as service manuals) more consistent and thus more understandable for the reader. When a technician replaces a "turn signal lamp" in a customer's car, for example, this designation should also appear on the bill and in the operating instructions, which may still be using the term "turn signal light" instead.

The Language Technology Processes and Methods Team is there to validate terminology and to direct and control how terminology is used. Validation is done in the DC Terminology Database. The basis for the validation procedure is a guideline that not only spells out rules for orthography and other criteria but also establishes procedures for conducting terminology research. Under a graduated timeline, more and more authors and editors are being granted the opportunity to submit terminology requests, so that in the end, the entire department will benefit from the standardization achieved. The terminologists process these requests, research the technical background related to the particular concept and then validate and define the term in accordance with the guideline. The concept, together with its equivalents in five foreign languages (English, French, Spanish, Italian and Japanese), is then approved in cooperation with the translation department.

Besides terminology work, content management systems have also assumed a central role within the Aftersales Section (a CMS is used, for example, to create diagnostic texts), so that terminology work is highly focused on exploiting the advantages of CMS.

\section{Cooperation between Industry and the University}

In 2005 and 2006, several projects were carried out in which Technical Communication students at the Karlsruhe University of Applied Sciences were given practical experience in terminology 
work at DC.

The students first attended a course designed to familiarize them with the basics of terminology theory and terminology work. Besides learning the important fundamentals (basics of LSP[3] research, the semiotic triangle, different types of concept systems and how to create them, working with definitions, rules on creating designations etc.), the students gave special attention to defining how a systematic, subject-specific terminology project should look under ideal conditions. The discussion examined what requirements would have to be fulfilled in order to produce flawless, "clean" terminology in line with terminology theory.

Following this orientation in terminological theory backed up by concrete examples, the project with DC started off with a number of all-day workshops that provided the participants with an introduction to terminology management as practiced in the company, as well as the opportunity to perform terminology work in small, closely supervised groups.

The university defined two primary objectives for its students:

To perform practical terminology work and apply the theoretical knowledge they have gained;

To experience first-hand, the gap between theory and practice, or to put it more precisely, between what is desired in the theoretical world and what is possible in the real world.

DC further attached the following expectations to this project:

To develop terminology for the company database in accordance with specific term validation requirements (nomenclature rules, vehicle-specific attributes) laid out by DC;

To provide a theoretical foundation for practical terminology work that could in future be routinely applied at DC to produce usable concepts and concept relations for the terminology database.

\section{The Process of Terminology Validation at DC}

Due to time constraints, the terminologist rarely has the chance to research and validate concepts prior to actually receiving a request to do so. Normally, such research is triggered by a request from an author who wishes to use a term in a text he or she is writing, but cannot find this term in the database. As authors are not authorized 
to create new terms, they must place a request for term approval in the terminology database. The author must not only specify the desired term, but must also write a definition for that term.

The ad hoc terminological research that predominates at DC is recognized by terminology theory, but it is a subject of controversy. If research concentrates only on isolated concepts without a holistic examination of the entire subject field the risk of error is high. Neighbouring concepts may not receive sufficient attention and they may not be properly delimited from the concept under examination. Under such conditions, it is also hardly possible to perform a meticulous analysis of applicable definitions.

Moreover, the need to "delve" back into a subject every time a new concept comes up for clarification can result in a lot of redundant work for the terminologist.

In light of the medium-term objective of establishing a comprehensive database, it is very regretful and detrimental to quality that ad hoc research and not systematic subject-related research is the rule at DC.

Added to this is the problem that authors sometimes lack the specialized knowledge required to properly define and process concepts.

The terminologists at DC are aware of this shortcoming in the practical implementation of their work. The problem becomes especially significant in cases where previously validated terminology needs to be changed, as this results in significant costs for text and translation management. As a consequence, research is done with the utmost care and diligence, and changes are the absolute exception.

On the other hand, it would appear neither prudent nor justifiable to invest time and money into work that does not produce a corresponding benefit. Such unrewarded expenditure would gravely undermine the acceptance of terminology work. The fact that years of preparatory work would be required in order to complete the necessary terminology work can be seen by looking at the current research being done on the word "Ventil" (valve). To gain a comprehensive overview of the designations used in the DC section, a text analysis covering all repair instructions was commissioned. The result is a list of over 2000 valve designations. Determining which terms are synonymous and creating a rough classification system for these terms would require that a terminologist works for weeks, if not months (full-time employment). Then comes the task of writing definitions before the hundreds of remaining terms are 
given to the translation staff for processing. Such work is not affordable under normal business conditions.

So, terminologists currently perform their research in response to the requests submitted. The first step is to check whether the requested designation is already in the database. If, for example, an author requests the term "turn signal light"[4], which is not among the approved terminology, the terminologist can see by the definition that the author is referring to TURN SIGNAL LAMP, defined as the luminous element on the vehicle that emits the turn signal light. In this case, the terminologist must then decide whether to add the concept TURN SIGNAL LIGHT (defined as the light emitted by the turn signal lamp) to the database, as this concept is also required by authors. In other cases, the terminologist will determine that the requested term is a synonym for a designation that is already in the database and will record it as such. Either way, the terminologist will reject the request and provide an explanation to let the author know which designation may be used in which context.

If, however, the requested concept is required but not yet in the database, the terminologist must decide whether the concept is so monosemous that it can be assigned a designation and a unique definition without the need for further relational research in accordance with the current guidelines.

The language level is also checked. The concept SEAT, for example, is too general and was split into DRIVER and FRONT PASSENGER SEAT. On the other hand, concepts that are too specific are incorporated into a superordinate concept.

The terminologist then assigns the required DC-specific attributes and conducts further checks, such as whether the marketing department has defined a particular orthographic rule for the designation. As several terminologists work with the database simultaneously, it is possible to assign a status to each concept, so that everyone can immediately see where the concept is on the process chain. Once the concept has been through the required processing stages, it is sent to the translation department for translation. 


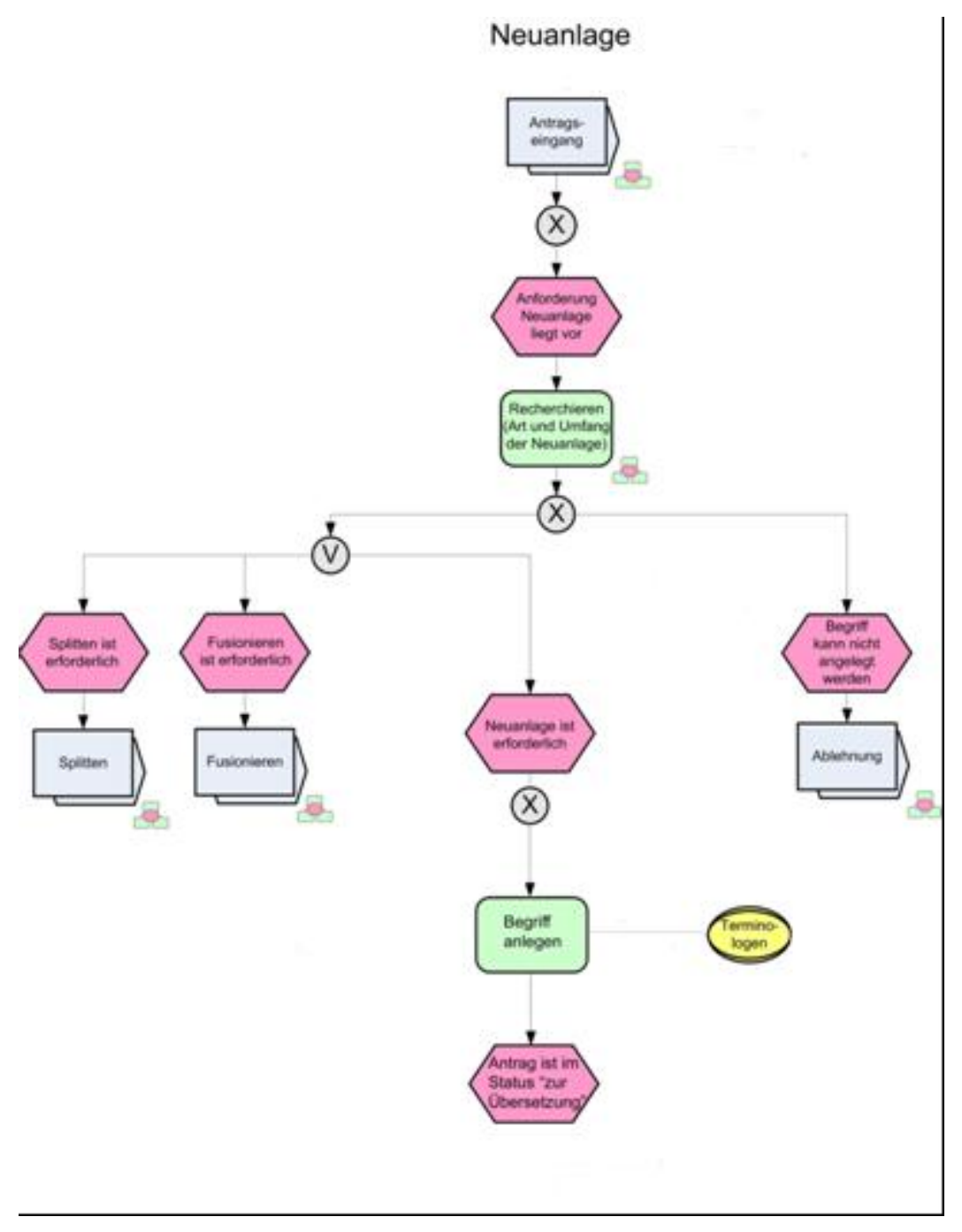

Fig. 2: Flow chart: "Adding New Terminology"

\section{Clash between Theory and Practice}

Now let's look at where the cooperative project with the university gave rise to confusion because the students were not able to apply the theory they had learned on a one-to-one basis. In other words, which aspects of terminology theory are not used in practice at DC?

The first issue to cause irritation was the fact that the terminology of terminology theory was not understood and used by everyone involved to the same degree. Within their general language environment, the DC employees in particular were not used to dealing with this specialized terminology in a consistent manner.

In German, it is very difficult to consistently differentiate between 
the words "Begriff" (concept) and "Benennung" (designation), since, in a general language context, the word "Begriff" is often used as a synonym for "Benennung" or "Wort" (word). At DC, statements like the following were not uncommon: "Finden Sie einen anderen Begriff für Sensor" or "Diese zwei Begriffe sind synonym". In both cases, the word "Benennung" should have been used instead of "Begriff".

The students, having just invested much effort in internalizing this difference, wanted to strictly differentiate between the two terms!

But more important than such slight misunderstandings were the more major departures from the approach demanded by terminology theory, and the approach as practiced at DC due to cost restraints and the question of relevancy.

\section{Basic Approach}

A distinction is made between three types of terminology work:

a) Ad-hoc research The objective here is to solve a specific terminological problem (e.g. in a concrete translation situation) in as short a time as possible. Broader knowledge is not expected to be gained through such research and there is a relatively high tendency to commit errors due to the time pressures involved.

b) Text-related research Here, the terminology found in an entire text is analyzed. The extent to which this text concentrates on a single subject field determines how reliable and rich the terminological yield will be.

c) Subject-related research This involves thoroughly investigating the terminology associated with a delimited subject field and describing the associated concepts. The results yielded here are not only the most extensive, they are also the most reliable, since the terminologist has delved deeply into the material, using comprehensive text corpora as the basis for research.

From their terminology course, the students were especially acquainted with the subject-related method of terminology work. The principal work that they wanted to perform in the DC project was therefore as follows:

- Study technical subject matter in order to understand all the interrelationships and to be able to identify and isolate concepts

- Develop concept systems that fully depict and systematize technical knowledge 
- Compile all existing designations and assign them to the concepts As described above, it was not possible to achieve compatibility between the work as planned by the students and the day-to-day operations at DC. Since research at DC is done in an ad-hoc manner in response to requests for specific terms, a thorough study of a complete subject area is neither possible nor desirable. Instead, the following task was given: "Examine the extent to which the term "seat" is relevant for DC's terminology."

The students wanted to carry out a systematic study for this limited topic field. They first created the following concept system, knowing that the system reflects in no way the variety of seats that exist at DC, but seeks only to depict the basic concepts and concept relationships.

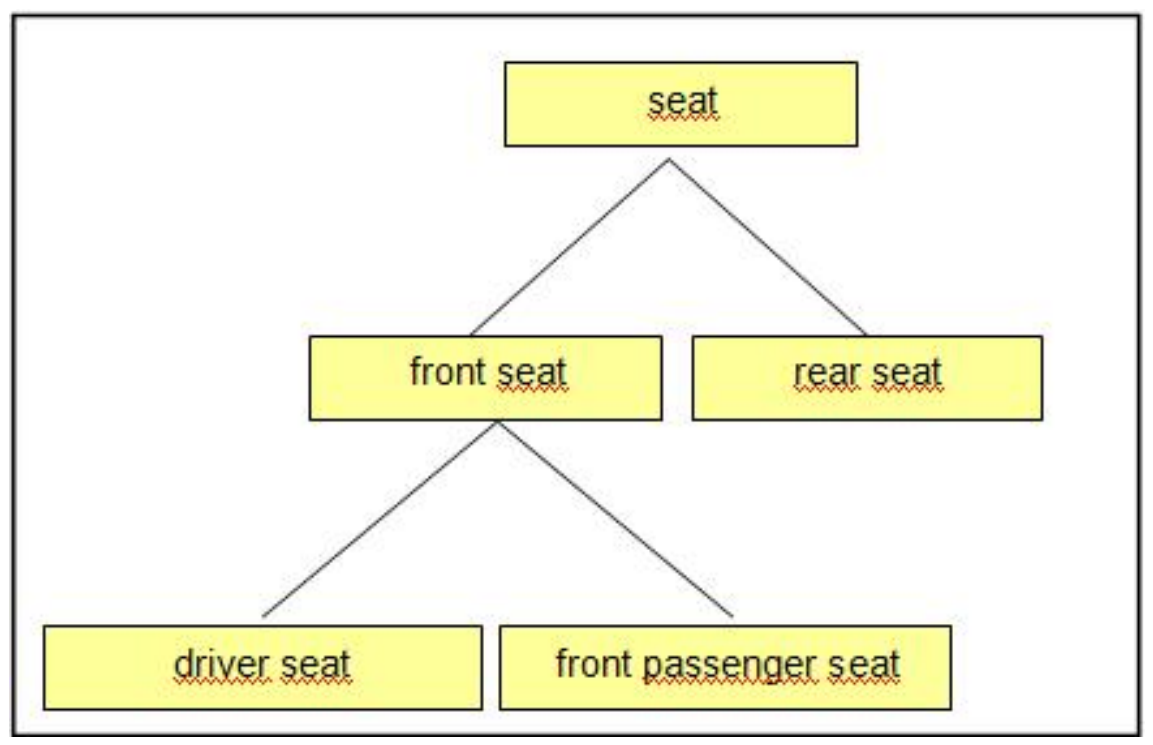

Fig. 3: Concept system for SEAT

All five concepts from this generic concept system were precisely defined based on the technical literature, set in relationship to one another and filed together with all the existing designations. The following criteria, taken from the relevant standards for terminology work and from terminology theory, were given the greatest weight when selecting the preferred term:

- Evaluation of the source in which designation was found for reliability and currentness (for qualitative evaluation of designation)

- Frequency with which designation occurs (for quantitative evaluation of designation)

- Quality of designation itself

For the third item, quality of designation, the following criteria from 
ISO 704/2000:25ff played an important role:

\section{Transparency}

"A term is considered transparent when the concept it designates can be inferred, at least partially, without a definition. In other words, its meaning is visible in its morphology."

\section{Consistency}

"The terminology of any subject field should not be an arbitrary and random collection of terms, but rather a coherent terminological system corresponding to the concept system. Existing terms and new terms must integrate into and be consistent with the concept system."

\section{Appropriateness}

"Proposed terms should adhere to familiar, established patterns of meaning within a language community."

\section{Linguistic economy}

"A term shall be as concise as possible. Undue length is a serious shortcoming. It violates the principle of linguistic economy and it frequently leads to ellipsis (omission)."

\section{Derivability}

"Productive term formations that allow derivatives (according to whatever conventions prevail in an individual language) should be favoured."

\section{Linguistic correctness}

"A term shall conform to the morphological, morphosyntactic and phonological norms of the language in question."

\section{Preference for native language}

"Even though borrowing from other languages is an accepted form of term creation, native language expressions should be given preference over direct loans."

From DC's perspective, however, the amount of work done by the students was overly excessive. At DC, concept systems are 
developed for problematic word fields only. For example, a great variety of retaining devices are used in DC vehicles. Some of these are named according to their function, others according to where they are installed in the vehicle. If research on a term reveals that a large percentage of designations from a particular field are not named uniformly, i.e. according to either installation location only or function only, then this entire field is subjected to detailed investigation.

Note from a theoretical perspective: at DC, the selection criterion of consistency dominates. Beyond that, the native language principle is applied and anglicisms are purposely avoided. All other quality criteria for designations are not applied.

Moreover, only internal company material is used for research, eliminating the need for researching in and, above all, evaluating external sources. This means that many rich sources - in particular specialized motor vehicle literature - are purposely not used.

There are highly divergent target groups for the terminology at DC. Whereas authors of customer information may use, for example, the designation "front seat", this designation is not suitable for workshop documents since a control unit may theoretically have to be labelled such that it is always installed under the driver seat, which may be installed on either the left or right side.

At DC, the concept SEAT was consequently rejected as being too general, while FRONT SEAT was rejected because it was possible to suitably depict this concept for all users by means of its two subordinate concepts. With the goal of maximum precision in mind, only the designations "rear seat", "driver seat" and "front passenger seat" are considered relevant and usable. The result for DC consists of the three preferred terms and the instruction that the terms "seat" and "front seat" (as well as their synonyms) are considered deprecated terms.

Therefore, the students here carried out two tasks that turned out to be superfluous from a practical point of view: research on definitions for the two more general concepts and the development of the concept system.

However, this work was meaningful and necessary not only as far as subject-related terminology work is concerned. Any ad-hoc research is risky as it does not incorporate an overall study of the subject matter, but such overall studies serve to give the terminologist a complete understanding of the topic at hand so that concepts can be properly delimited from one another. The research done in developing definitions for the concepts SEAT and FRONT 
SEAT was also an important part of this process. These definitions should be archived in the company's terminology database to serve as helpful reference aids, even though the corresponding designations were barred from use. These definitions are also sources of important conceptual information for technical writers during text production.

\begin{tabular}{l|l}
\hline pproach and Objectives of Students & Approach and Objectives of DC \\
\hline $\begin{array}{l}\text { Concept-oriented approach } \\
\text { Subject-related approach }\end{array}$ & $\begin{array}{l}\text {-Designation-oriented approach (respond } \\
\text { requests from technical authors) } \\
\text { Researching, naming and defining ALL concepts } \\
\text { lithin a particular topic field }\end{array}$ \\
$\begin{array}{l}\text {-Development of complete concept systen } \\
\text { possible during normal business operations } \\
\text {-Certain levels within concept system ser } \\
\text { no useful role in editorial system } \\
\text {-Concept systems created only for } \\
\text { problematic word fields }\end{array}$
\end{tabular}

Tab. 1: Differences in Approach

\section{Concept Definitions}

The next area of conflict was the question of how to deal with concept definitions.

To ensure the correctness of their definitions, the students followed the teachings of terminology theory and researched the relevant specialist literature. They paid special attention to the following criteria, which had to be fulfilled by the specialist literature used:

- Reliability of source and competence of author (official standards and specialist books were the primary sources)

- Currentness (in order to avoid obsolete terminology or outdated definitions)

- Native language principle (in order not to simulate the conceptual structures of other languages)

Definitions found in these sources were added to the terminology database in the form of literal quotes. Bibliographic information was given for all quoted sources in order to document and make 
verifiable the origin of the quoted material.

Now let's compare the students' approach to the main requirements set by DC for concept definitions. These are:

- Immediate utilizability

- Brevity

- Connection to DC

In order to fulfil these requirements, definitions at DC are formulated directly by the technical author or the terminologist. There is therefore no need to quote sources. It is important that definitions be written in a brief and lucid style, since these definitions are supplied to the authors when they are writing documents and have to select the correct concept.

The technical correctness of definitions is often only researched to the point, sufficient enough to satisfy the requirements within the DC context. The question is raised, for example, as to whether the German term "Wartungsarbeit" in the sense of a finite amount of maintenance work that can be timed and billed ("maintenance operation") should be considered synonymous with "Wartungsarbeit" in the general, indefinite sense ("maintenance work"). These are two different concepts. If, however, this difference is irrelevant to the texts produced, then there is no need for it to be manifested in the form of two separate concepts.

Since the definitions written by the authors are checked for their correctness by technical specialists at DC, this process is also acceptable from a terminology theory perspective. What remains critical is the superficial technical check for correctness that was accepted from the start and the conscious decision not to create complete concept systems and definitions.

Even more critical from a theoretical perspective are the two other requirements for definitions, namely the connection to DC and the desired brevity.

Certainly, extensive definitions are not always required, but the pressure of applying a predefined limit on definition length can easily lead to the omission of relevant concept characteristics.

Moreover, terminology theory demands that terminology work must first of all be descriptive and precisely describe language usage and concepts as they currently exist within the subject field under consideration and within the entire language community. Only then can one start to work on standardizing terminology, for example, by barring certain designations within a company, in order to improve textual consistency. 
At DC, however, the criterion of "connection to the company" is placed above all others. Standardization is taking place not only at the designation level, but also at the concept level! It may therefore, occur that concept definitions are created which differ from the definitions applied elsewhere in the field. This approach results in the creation of a company-specific set of concepts and designations that do not always coincide with the LSP used outside the company. From a theoretical perspective, this result is unacceptable.

The major advantage of this approach (from DC's perspective): each definition is written in German and translated on a one-to-one basis. As a consequence, the definitions also apply in all languages into which the company translates its materials (see next section).

\section{Multilingual Terminology Work}

As previously indicated in the discussion on definitions, the greatest gap between theory and practice was experienced in the area of multilingual terminology work.

Let's first take a look at how multilingual terminology work should be carried out in theory.[5]

The first step is to compile and systematize all concepts, definitions and designations in the first[6] language. The next step is to compile and systematize all concepts, definitions and designations in the second language, independent of the results of the research conducted for the first language.

Research in both languages is done using original-language documents only, in order to ensure that all expressions recorded for either language are truly typical (idiomatic) and that all concepts and concept relations actually exist in the environment of the language under investigation. If the terminologist uses translations instead of original-language texts, he or she runs the risk of picking up concepts from other language or cultural environments that have simply migrated into the texts through the translation.[7]

In the third step, the two separate results are compared with one another to determine where full, partial or zero conceptual equivalence exists. This comparative analysis is based on the concept systems, which depict the relationships of concepts to one another, and, more importantly, on the definitions. For it is the definitions that reveal whether all relevant concept characteristics exist in both languages or whether there are decisive differences.

Direct mapping (one-to-one matching) between the two languages 
exists whenever there are official or internationally recognized definitions that include the same characteristics in all languages. This is often, but far from always, the case with languages for special purposes. Each language has its own system of concept formation and linkage that has developed naturally within the unique historical and cultural environment of that language.

Putting such an approach into practice at DC is not feasible as it would result in significant costs and, above all, make it impossible to supply terminology to the authors within an acceptable time frame, since the translation process is a direct link in the terminology supply chain. As it stands now, authors normally submit a request for a German concept. The terminologist then decides whether to approve the concept on its own, or to conduct research on related concepts. For single concepts, the terminologist immediately selects a designation and writes a definition that meets the internal requirements of DC. Synonyms, if known, are added. These are not explicitly researched, but arise over time, most often from requests submitted by authors at a later date.

This package (concept definition and the suggested German designation, including all necessary annotations) is sent out for translation. The staff working on the translation includes one terminologist, who coordinates the process of finding equivalents in five standard languages based on the definitions supplied.

The translations are then placed in the foreign-language section of the terminology database. Due to time constraints, the definitions are currently only translated into English.

In line with the requirements for multilingual terminology work described above, theory demands that the definitions be researched separately in both languages and these then examined to see to what extent they overlap. The comparison of definitions[8] (e.g. German vs. English) should be the rule, and not the translation of definitions. The DC approach, however, clearly attributes excessive importance to German as the source language. DC uses the German concept as the starting point and simulates this concept in the other language environments.

From a terminology theory perspective, this approach is only acceptable for concepts that are newly created at DC and which are as yet not known within other language environments. In this case, the concept would be defined for its original German environment and then (together with its definition), transferred to other language environments. The original German definition thus becomes the basis for producing the concept in the other language environments. A translation of the German designation into other 
languages would also be conceivable here.

If, however, the concept in question or at least similar concepts already exist in the other language environments, terminology theory would demand that these existing concepts and their designations always be granted "priority".

Each of the five translators (for the five standard languages mentioned) provides either positive or negative feedback to the translation coordinator as to whether or not a direct equivalent can be found in the other languages for the concept in question.

At this stage, it becomes clear that DC does not differentiate between concept gaps and designation gaps. In terminology theory, however, this difference is very important.

If a designation gap exists, a particular concept is known in the second language or language community and the task is "merely" to find a matching designation.

A concept gap, however, requires that the entire concept first be established in the second language community because no corresponding concept exists due to differences in the way users of the second language structure reality in their minds.

Each type of gap must be dealt with using a different approach, but this is not done in DC practice.

The translation department researches the concept relations within the foreign languages that must be taken into account in order to establish equivalence, and submits proposals to the terminologist responsible for the German concepts as to how these concepts would have to be modified (usually through further specification), so as to achieve equivalence in all languages. These changes are applied in all cases so that in the end, we achieve exact equivalence in the five languages. Once this process is complete, the translation department approves the concept, which can then be used by authors in their documents.

As criticized above in the discussion on the translation of German definitions into English, this issue again highlights the fact that the basic methodology taught by terminology theory for dealing with partial equivalences, is being circumvented and the differences between the linguistic realities of two individual languages ignored.

"Due to the nature of language itself, terms selected from more 
than one natural language vary in the extent to which they represent the same concepts. These variations can be regarded as forming a continuum, one end of which is represented by terms which can, for the practical purposes of indexing, be regarded as exact equivalents, further points being marked by various degrees of partial or inexact equivalence, and the final point being represented by those extreme situations in which a term in one language refers to a concept which cannot be expressed by a single, direct and equivalent term in another language." (ISO 5964/1985:7f).

These graduated distinctions have been organized into five relatively broad categories (ISO 5964/1985:8):

"Case 1 - Exact equivalence: The target language contains a term which is a) identical in meaning and scope to the term in the source language; b) capable of functioning as a preferred term in the target language.

Case 2 - Inexact equivalence: A term in the target language expresses the same general concept as the source language term, although the meanings of these terms are not precisely identical.

Case 3 - Partial equivalence: The term in the source language cannot be matched exactly by an equivalent term in the target language, but a near translation can be achieved by selecting a term with a slightly broader or narrower meaning.

Case 4 - Single-to-multiple term equivalence: The term in the source language cannot be matched exactly by an equivalent term in the target language, but the concept to which the source language term refers can be expressed by a combination of two or more existing preferred terms in the target language.

Case 5 - Non-equivalence: The target language does not contain a term which corresponds in meaning, either partially or inexactly, to the source language term." 
These graduated levels of equivalence are ignored at DC. Instead, exact equivalences are established artificially in every case.

For multilingual terminology work, the German definitions are sometimes translated into other languages, thus premising or artificially sanctioning the German concept system. In other cases, however, the process works in the other direction and the German concept definitions are adapted (usually narrowed) to match the concept definitions of the foreign languages.

Neither approach is compatible with the principle of linguistic relativity or with the terminological knowledge of the differences in the concept systems between various languages.

\section{Conclusion}

The joint project between DC and the Karlsruhe University of Applied Sciences was very fruitful for everyone involved.

- The students were able to learn how project management and teamwork function in the terminology field, and where the requirements of terminology theory were applied at DC and where they were not.

- Likewise, DC gained positive input: the students elaborated the technical concepts in the subject fields so completely and with such a high degree of quality, that it was possible to place a large portion of these concepts directly into the database. In addition, discussions with students raised interesting questions concerning both the guidelines for validating terminology and the existing database model. Some of the ideas that came to light here led to the addition and optimization of features in the database.

- With respect to teaching, the following primary conclusion can be drawn: lecturing on the ideal case scenario for practical terminology work is certainly very helpful. This is the only way to ensure that students working in the field do not start off with a half-hearted attitude to the job and make too many compromises that impair quality. They need to learn about the issues that demand the attention of the terminologist and about the problems associated with multilingual terminology management and how to deal with them. But the teaching staff must also clearly point out, that the methods taught at universities may not be feasible in practice due to cost or time constraints. 


\section{Authors}

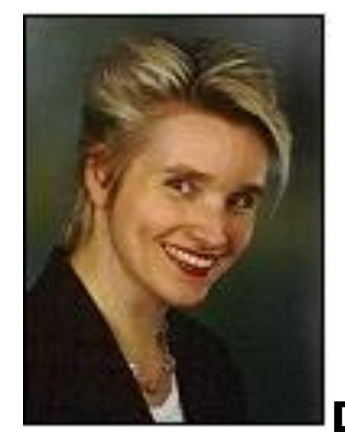

Dr. Petra Drewer is Professor at The Karlsruhe University of Applied Sciences, Germany

mailto:petra.drewer@hs-karlsruhe.de

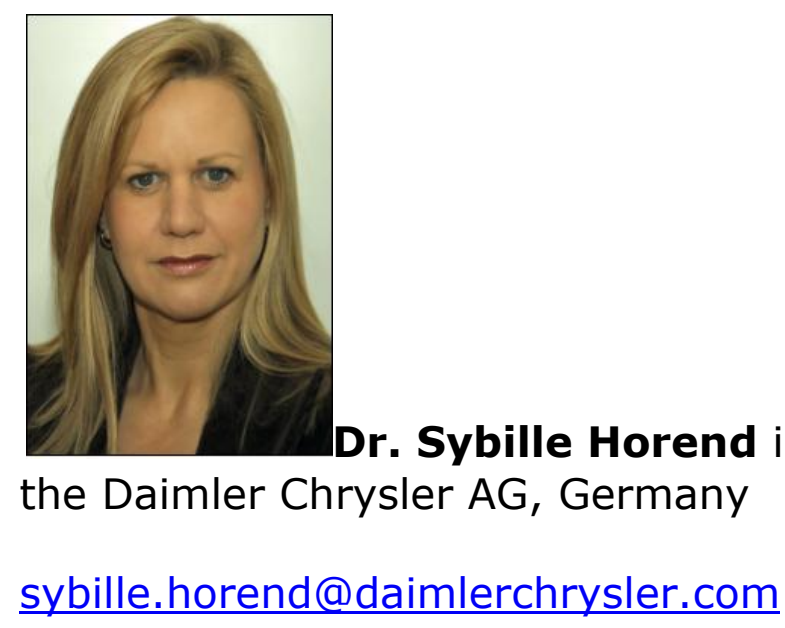

\section{References:}

Arntz, Reiner / Picht, Heribert / Mayer, Felix (2002): Einführung in die Terminologiearbeit. 4., gründlich überarb. Aufl. Hildesheim : Olms (Studien zu Sprache und Technik 2)

ISO 704 (2000): Terminology Work: Principles and Methods.

ISO 860 (1996): Terminology Work: Harmonization of Concepts and Terms.

ISO 5964 (1985): Documentation - Guidelines for the Establishment and Development of Multilingual Thesauri

Küdes (2002): Empfehlungen für die Terminologiearbeit. 2. überarb. und erw. Aufl., hrsg. von Konferenz der 
Übersetzungsdienste europäischer Staaten. @ Schweizerische Bundeskanzlei Sektion Terminologie, Bern

[1] In contrast to ISO 704 that uses "terminology" in the singular and without an article in order to designate the discipline, "terminology" used in the plural, or preceded by an article, refers to the set of designations of a particular subject field (ISO 704/2000:vi), we make use of the following designations:

- "Theory of terminology" (terminological teachings, research and science)

- "Terminology management / terminology work" (practical application)

- "Terminology" (set of designations of a particular subject field)

[2] Deprecated synonyms must never be removed from the terminology data because the technical writer, or the translator needs to be able to look up terms and check which terms are synonyms and which term designates which concept, etc.

\section{[3] LSP = language for special purposes}

[4] To clearly distinguish between concepts and designations in this paper, designations have been placed in double quotation marks while concepts are written in upper-case letters.

[5] Here again, the approach is based on subject-related terminology work.

[6] I purposely do not differentiate here between source and target language, since these expressions imply that translation takes place. I refer instead to a first and second language, the order of which should be interchangeable in "clean" terminology work.

[7] This methodology is what I call the native-language principal in terminology work. Besides this method, there is a second type of native-language principle which states that terminological analysis in a particular language should always be carried out only by native speakers of that language.

[8] Each language would have to be compared with each other language separately.

This article was uploaded to http://www.languageatwork.eu in July of 2009 and published under a "Creative Commons license Attribution Non-commercial (by-nc)" for more information please go to: http://creativecommons.org/about/license/ 